\title{
Peruzzotti, Enrique y Martín Plot (editores) (2013). Critical Theory and Democracy. CiVIL SOCIETY, DICTATORSHIP, AND CONSTITUTIONALISM IN ANDREW ARATO'S DEMOCRATIC THEORY. ROUTLEDGE
}

\author{
Claudia Heiss (Cheiss@iap.uChile.cL) \\ UNIVERSIDAD DE CHILE
}

- Qué tienen que ver las transiciones de Europa del Este y la reconstrucción de Irak; las teorías del constitucionalismo, la sociedad civil, el gobierno de emergencia y la dictadura? En todos estos temas Andrew Arato ha formulado aportes conceptuales fundamentales. Sus estudiosos generalmente llegan a él por alguno de ellos. Pero es raro que alguien trabaje igualmente con sus libros sobre estos distintos aspectos.

La compartimentalización de hecho de su influencia intelectual se suma a la dificultad analítica que significa intentar unificar el pensamiento aratiano en una línea coherente. Si hay autores que desarrollan toda su obra en torno a un concepto -la democracia moderna para Robert Dahl, el capital social para Robert Putnam-, las publicaciones de Andrew Arato parecen ir de un tema a otro, dando el puntapié inicial a ideas que luego se expanden, a través de otros autores, en distintas direcciones. Y así como es difícil situar la obra de Arato en torno a un único objeto de estudio, también es complejo identificarlo con una sola disciplina o con un método particular. En él confluyen con fuerza la teoría política, la política comparada, el análisis jurídico y la sociología.

Un gran logro de Critical Theory and Democracy: Civil Society, Dictatorship, and Constitutionalism in Andrew Arato's Democratic Theory (Routledge, 2013) es precisamente develar la coherencia implícita en las distintas ramificaciones que tiene el pensamiento de este autor. Dos de sus ilustres discípulos en la New School for Social Research -la universidad que en los años 30 recibiera en Nueva York a los refugiados de la Escuela de Frankfurt que huían de la guerra europea-, los argentinos Enrique Peruzzotti y Martín Plot, emprendieron el esfuerzo titánico de reconstruir la obra de su profesor en este volumen editado que contiene además un ensayo inédito del propio Arato sobre el concepto de dictadura. Gracias a la participación de distintos 
autores, el libro logra expresar esa pluralidad y al mismo tiempo develar el elemento común a la obra de Arato.

El marco conceptual del libro y de la trayectoria intelectual de Andrew Arato se resumen acertadamente en el título: "Teoría Crítica y Democracia". Si hay un elemento unificador es el proyecto emancipador de la teoría crítica y su aplicación en el contexto de un sólido compromiso con la democracia. La tradición de la teoría crítica concibe la investigación social como orientada a un objetivo práctico: la liberación humana de todas las formas de opresión. Las preocupaciones de Arato, desde sus comienzos con el post-marxismo y el estudio de las ideas del húngaro George Lukacs hasta sus análisis actuales sobre constitucionalismo, poder ejecutivo, gobierno de emergencia y dictadura, dan cuenta de esta interacción entre teoría e instituciones sociales y políticas. La reflexión conceptual parece siempre estar en última instancia al servicio de la libertad y la autodeterminación en términos bastante prácticos.

Los ensayos que componen el volumen se dividen en tres secciones. En la primera parte, cinco autores, caracterizados como "compañeros de ruta" de Arato por haber desarrollado sus teorías e intereses en paralelo con el autor, analizan la influencia de su obra en distintos aspectos de la teoría constitucional contemporánea. La segunda parte se compone de cinco artículos escritos por discípulos de Arato que han aplicado su esquema conceptual al estudio de fenómenos como la sociedad civil, el populismo y el poder ejecutivo en América Latina. La tercera parte es un ensayo inédito del propio Andrew Arato sobre la historia del concepto de dictadura, precedida por un análisis de los editores sobre el tema. Como apéndice, se ofrece el listado completo de la bibliografia de este autor.

¿Por qué un libro-homenaje a Arato? Para quienes hemos tenido el privilegio de estudiar con él, parece evidente que la profundidad de sus reflexiones y la amplitud de una mirada poco convencional a los problemas más apremiantes de la sociedad y la política contemporánea ameritan el esfuerzo por sistematizar y conceptualizar un legado intelectual de proporciones inusuales en la academia de hoy.

Emigrado desde Hungría a Estados Unidos en su temprana juventud, Arato siempre mantuvo un nexo con la política centroeuropea. Sus primeros trabajos fueron sobre la revisión del pensamiento marxista y la Teoría Crítica. De ese período resultaron The Young Lukacs and the Origins of Western Marxism (1979) y el influyente The Essential Frankfurt School Reader (1982). Entre fines de los 80 y comienzos de los 90 escribió sobre el fin de los regímenes socialistas y publicó dos libros sobre el tema: uno en torno a Gorbachov y otro sobre el proceso de reforma en la ex órbita soviética. En 
1992 publicó, junto a Jean L. Cohen, su libro más citado: Civil Society and Political Theory (The MIT Press), donde combina el concepto de esfera pública de Jürgen Habermas con el papel de distintas manifestaciones de la sociedad civil en las transiciones a la democracia en países como Polonia, Checoslovaquia y Hungría. De ese período es también From Neo-Marxism to Democratic Theory. Essays on the Critical Theory of Soviet-Type Societies (1993).

De sus intercambios con Habermas surgió el volumen editado Habermas on Law and Democracy (1998) y finalmente su texto decisivo sobre constitucionalismo, Civil Society, Constitution, and Legitimacy (2000). Arato plasmó en diversos artículos sus reflexiones sobre problemas constitucionales de la contingencia política estadounidense, incluida la doctrina Bush tras los ataques del 11 de septiembre que destruyeron las Torres Gemelas a pocas cuadras de su casa y su universidad. Más recientemente, estos intereses desembocaron en Constitution-Making under Occupation: The Politics of Imposed Revolution in Iraq (2009).

El libro editado por Peruzzotti y Plot ofrece reflexiones particularmente relevantes al Chile de hoy, sumido en el debate sobre la legitimidad de una constitución diseñada por la dictadura militar de Augusto Pinochet y modificada a través de varios procesos de reforma que sin embargo no han logrado convertirla en un acuerdo social con suficiente adhesión popular ni política. Los cuestionamientos de Arato a la relación entre poder constituyente y poder constituido y al concepto de soberanía, así como sus análisis sobre el papel de la sociedad civil, ofrecen matices conceptuales muy relevantes a este debate político. Adicionalmente, sus trabajos más empíricos sobre procesos de transición pactada en Europa del Este y América Latina, así como sus críticas al presidencialismo, especialmente frente a situaciones de crisis, son muy pertinentes a esta discusión.

El debate constitucional en Chile se ha caracterizado por un sesgo fuertemente jurídico y más bien de carácter nacional. Es de esperar que la publicación de este libro contribuya a difundir entre nuestros intelectuales una mirada distinta, que enriquezca el análisis no sólo con la experiencia comparada en materia de cambio constitucional, sino también con un enfoque teórico y multidisciplinario como el que ofrece el trabajo de Andrew Arato.

Tanto en su célebre formulación sobre la sociedad civil, desarrollada junto a Jean Cohen, como en sus injustamente menos populares estudios sobre constitucionalismo, Arato formula una visión fuertemente pluralista, opuesta a visiones totalizantes que buscan resumir en una voz unitaria la voluntad popular. Arato emerge como 
un escéptico frente a visiones mesiánicas que llaman a escuchar esa supuesta voz del pueblo y rechaza los proyectos revolucionarios de izquierda o de derecha que se proponen partir de cero en la construcción de una nueva realidad social. Junto con rechazar las sociedades de estilo soviético, se opone a los proyectos refundacionales de cualquier signo político que parten de una noción sustantiva de soberanía para producir un quiebre total con el pasado jurídico e institucional. Es en esta lectura radicalmente reformista que confluyen el constitucionalismo y el papel de una sociedad civil autónoma respecto del estado y del mercado.

A nivel conceptual, el rechazo a la vía rupturista de elaboración constitucional surge de observar -en la lectura de autores como Hannah Arendt, Carl Schmitt, Clinton Rossiter, Bruce Ackerman y Carl Friedrich, entre otros - un nexo entre revolución, poder constituyente y dictadura o gobierno de emergencia. El poder constituyente como voz soberana que rompe con toda la legalidad preexistente se expresa en un régimen excepcional y dictatorial, ya sea de corte militar, oligárquico o proletario. Al tomar el poder, los proyectos revolucionarios inevitablemente desmovilizan y suprimen las formas de organización social que los levantaron y se convierten en autoritarios.

Contra el mito del poder constituyente unívoco, Arato propone una teoría sobre la transformación social y política compleja, llena de las contradicciones inherentes a la reforma desde la legalidad existente y característica de las transiciones pactadas. En este contexto, la sociedad civil con su pluralidad juega un papel fundamental en la construcción de una institucionalidad verdaderamente democrática. Sociedad civil y constitucionalismo se presentan como dos caras de un mismo fenómeno. Los actores y las instituciones de la sociedad civil requieren un marco constitucional capaz de garantizar la protección de derechos fundamentales para desarrollarse y al mismo tiempo proveen al régimen constitucional de una esfera social donde existir. Rechazando la versión revolucionaria y sus consecuencias autoritarias, Arato se propone crear una teoría democrática de la soberanía popular en torno a la tensión entre poder constituyente y poder constituido.

Esta forma de entender el problema aporta al contexto chileno un enfoque novedoso. Los modelos revolucionarios tienden a poner el énfasis en el poder constituyente mientras que las versiones más conservadoras enfatizan el orden existente en la forma del poder constituido, donde la capacidad de cambio del poder constituyente queda prisionera de la correlación de fuerzas consagrada en las instituciones.

Aunque el proceso constitucional liderado por Jaime Guzmán tuvo tintes claramente revolucionarios, en el sentido de romper con la tradición legal previa y usar para 
ello un gobierno dictatorial que -en su primera fase al menos- se declaraba como de emergencia o como "estado de excepción", su legado institucional suprime cualquier posibilidad de expresión del poder constituyente. El artículo $5^{\circ}$ de nuestra Constitución señala en forma bastante confusa que el poder constituyente reside en la nación, y que se ejerce por el pueblo a través de elecciones y plebiscitos, y también a través de las autoridades señaladas en la constitución, es decir, a través del poder constituido. Esta formulación, donde el poder constituido puede hablar por el constituyente, amerita reflexión y debate. La obra de Andrew Arato, elaborada a partir de la tensión entre poder constituyente y poder constituido y el problemático paso del uno al otro, es un buen punto de partida para dicha discusión.

\section{Referencias bibliográficas}

Arato, Andrew (2009). Constitution-Making under Occupation: The Politics of Imposed Revolution in Iraq. USA: Columbia University Press.

Arato, Andrew (2000). Civil Society, Constitution, and Legitimacy. Lanham: Rowman \& Littlefield Publishers.

Arato, Andrew (1993). From Neo-Marxism to Democratic Theory. Essays on the Critical Theory of Soviet-Type Societies. USA: M.E. Sharpe.

Arato, Andrew y Eike Gephardt (1982). The Essential Frankfurt School Reader. NY: Continuum International Publishing Group.

Arato, Andrew y Paul Breines (1979). The Young Lukacs and the Origins of Western Marxism. NY: Seabury Press.

Cohen, Jean L. y Andrew Arato (1992). Civil Society and Political Theory. Cambridge: The MIT Press.

Fehér, F. y Andrew Arato (eds.) (1989). Gorbachev: The Debate. Atlantic Highlands: Humanities Press International.

Fehér, F. y Andrew Arato (eds.) (1991). Crisis and Reform in Eastern Europe. New Brunswick: Transaction Publishers.

Rosenfeld, M. y Andrew Arato (1998). Habermas on Law and Democracy: Critical Exchanges. Berkeley: University of California Press. 